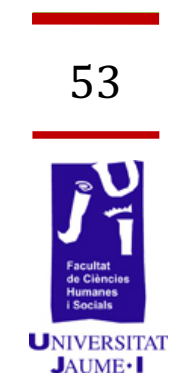

\title{
La irrupción de la neurociencia en el proceso jurisdiccional. Razones para un debate filosófico
}


Los recientes avances en neurociencia han generado un intenso debate doctrinal entre neurocientíficos, filósofos y juristas, que se centra en la cuestión de si el Derecho penal que hasta ahora conocemos está necesitado de una revisión profunda y una modificación sustancial de algunos de sus fundamentos. El debate se extiende también hacia el Derecho procesal, pues desde la perspectiva neurocientífica, comienzan a cuestionarse multitud de aspectos que afectan al proceso, como la prueba testifical, la detección de mentiras en el proceso, o la medición del dolor indemnizable, aspectos todos ellos que nos obligan a emprender un debate filosófico sobre la necesidad de armonizar las normas procesales con los nuevos datos con los que ahora se cuenta sobre el funcionamiento del cerebro.

PALABRAS CLAVE: Neurociencia, Derecho penal, proceso jurisdiccional, prueba testifical, medición del dolor

\section{Introducción}

La neurociencia ha tratado de retomar el debate filosófico sobre determinismo, indeterminismo y libre albedrío, afirmando que la libertad no es más que una ficción cerebral (RUBIA: 2009,11$)$ y que el hombre se halla sujeto a un fuerte determinismo (Pérez Manzano, 2011:2), de modo nadie es realmente capaz de elegir entre actuar de un modo o de otro para adaptar su comportamiento a las normas sociales, donde la libertad de voluntad sería una mera ilusión y el mal un fenómeno biológico que reside en el cerebro (Demetrio Crespo, 2011: 3). La idea parte de los experimentos de Libet en la década de los 80 del siglo XX, que constataron que el proceso de decisión y ejecución de un acto voluntario concreto tan solo es aparente, porque existe una actividad cerebral inconsciente, previa a la actividad cerebral consciente, y ello implica que el ser humano carece de efectivo control sobre sus actos tratando de confirmar que no existe distinción entre acciones $u$ omisiones voluntarias e involuntarias, y la conciencia es una instancia supervisora que decide si ejecuta o no la acción ya iniciada en el proceso cerebral inconsciente, a través de una especie de «derecho de veto por parte de la conciencia» (Libet, 1985: 522-539). Más recientemente John-Dylan Haynes, utilizando un escáner de resonancia magnética nuclear funcional (fRMI), ha venido a demostrar que hasta diez segundos antes de que la persona sea consciente de la decisión, el cerebro ya la ha tomado, y siete segundos antes de esa decisión, ya se puede predecir el movimiento (Soler Gil, 2009: 543-544). Todas estas cuestiones han venido generando un intenso debate doctrinal sobre la legitimidad del sistema penal que actualmente conocemos y sobre si sería conveniente una reformulación de algunos de sus postulados esenciales, que por el 
momento parece decantarse sobre la inexistencia de pruebas suficientes para dar ese paso (Balbuena Pérez, 2013: 134-136).

No obstante, la incidencia de los descubrimientos neurocientíficos en el ámbito del Derecho no se agotan en el Derecho penal, sino que también se extienden -entre otros muchos aspectos jurídicos de los que ahora no me puedo ocupar- al Derecho procesal, en el sentido de que las técnicas de neuroimagen podrían constituir una herramienta útil e importante para detectar las mentiras de los testigos o para medir el sufrimiento de una víctima a efectos de fijar con precisión la indemnización. De todas estas cuestiones me ocupo en el presente trabajo, aportando las más relevantes posiciones doctrinales sobre la materia, para terminar ofreciendo una opinión personal sobre la existencia de una serie de razones para emprender un debate filosófico sobre la conveniencia o no de transformar las normas que rigen el funcionamiento del proceso jurisdiccional.

\section{Neurociencia y proceso jurisdiccional}

La neurociencia tiene una incidencia importante en el ámbito jurisdiccional, que se extiende a todos los procesos -no solo a los penalesy la constatación de su utilidad podría producir una trasformación importante de aspectos tan esenciales como la valoración de la prueba, que nos conducirían no solo a cuestionar la validez y legitimidad del actual modelo jurisdiccional, sino también nos obligarían a modificar sustancialmente muchos aspectos para su correcto anclaje en el actual estado de la ciencia. Veamos con detenimiento algunos de estos aspectos.

\subsection{La prueba testifical}

La prueba testifical es uno de los medios probatorios más utilizados en el ejercicio de la potestad jurisdiccional (Gómez Colomer, 2014: 290 a 300), pues los testigos presenciales suelen ser decisivos en determinados procesos en los que la existencia de detalles precisos o la presencia de datos contradictorios, pueden condicionar la dirección que habrá de tomar el fallo del tribunal. La credibilidad de los testimonios y el valor que quepa otorgar a este medio de prueba, ha sido objeto de numerosos estudios en el ámbito de la Filosofía del Derecho (Bentham, 1843: 27 y ss.), aunque el debate no parece haber alcanzado todavía una solución satisfactoria. No obstante, deberíamos preguntarnos si con los conocimientos que ahora se tienen sobre la imperfección del funcionamiento de la memoria (Schacter, 1999: 15 y ss.) y de la frecuencia con la que el cerebro genera recuerdos falsos (Diges, 1997: 17 y ss.), debe seguir teniendo la importancia que se le otorga y si no sería conveniente la introducción de nuevas técnicas en el proceso para detectar determinadas cuestiones o incidencias en el propio testigo. De esta cuestión se ha ocupado Gazzaniga que explica que el cerebro confecciona una biografía inexacta, debido a que solo recupera información de las cosas orgánicas con la finalidad de adaptación y de 
supervivencia, por lo que almacena la información esencial pero no los detalles. Por otra parte, el cerebro genera recuerdos falsos, detalles distintos y genera una fusión de recuerdos y, a su vez, confusión. Este autor relata que debe haber un lugar en los tribunales para la neurociencia, ya que las imperfecciones de la memoria hacen que las personas sean idóneas para experimentar distorsiones en los recuerdos que, por otra parte, son conocidos tanto por abogados como por la policía y por los jueces, pero los tratan como si fueran una excepción. Por ello, afirma que la prueba de testigos podría cambiar radicalmente y que «se acerca el día en que se considerará poco ético recurrir a un testimonio por su naturaleza imperfecta». Muchos estudios han constatado las variaciones en el modo en que nos traiciona la memoria, por lo que deberían emplearse nuevas técnicas para minimizar sus efectos (Gazzaniga, 2006: 133-134). No conviene olvidar que las distorsiones memorísticas tienen un coste elevado para el sistema, pues no son pocos los supuestos en los que las personas han testificado en un determinado sentido estando totalmente convencidas de que decían la verdad, cuando en realidad los hechos ocurrieron de otra manera.

Gazzaniga indica que los errores memorísticos pueden corromper la memoria en cualquiera de sus fases, bien en la propia codificación de un recuerdo o bien cada vez que se recupera la información o se activa el recuerdo, de modo que algunos errores añaden información que no es verídica, propiciando los llamados errores de obra; y otros errores -los de omisión- suprimen información. Dentro de estas dos categorías, los errores memorísticos según el modelo de Daniel Schacter (Schacter, 2003: 11 y ss.), influyen de forma distinta en los procesos jurisdiccionales, errores que, en esencia, son: 1) Los recuerdos fugaces que se deben a que falta información a causa de que el recuerdo se diluye con el tiempo, o a que la información no fue codificada debidamente en el momento en que tuvo entrada en la memoria; por eso, Gazzaniga señala que los juicios que se celebran varios años después de los hechos, presentan graves inconvenientes para la prueba testifical, ya que los testigos pueden haber perdido la mayor parte de los recuerdos sobre esos hechos o incluso tenerlos distorsionados (Gazzaniga, 2006: 135-136). 2) La distracción, que se produce cuando no se presta suficiente atención para retener ciertos datos, como sucede cuando no se encuentran las llaves o no se recuerdan los nombres de las personas. Esto ocurre porque no se codifica bien el recuerdo debido a la falta de atención, por ese motivo, es frecuente que a pesar de haber sido testigo presencial de unos hechos, en el momento de prestar declaración no sea capaz de recordar esos detalles (Gazzaniga, 2006: 136). 3) El bloqueo, también denominado «síndrome de la punta de la lengua», que consiste en que la persona está segura de conocer un dato concreto pero no puede extraer esa información de forma voluntaria en ese momento. Esto plantea problemas en el ámbito de la jurisdicción, porque en el interrogatorio de un testigo puede suceder que conteste de forma muy precisa a ciertos detalles de los hechos que haya podido presenciar, pero si se le pregunta por otros detalles posteriores, es posible 
que el recuerdo de los primeros esté bloqueando el recuerdo de los segundos. (Gazzaniga, 2006: 136-137). 4) La falsa atribución, que se produce cuando el cerebro introduce recuerdos falsos que se infiltran entre los recuerdos reales. Es el caso de la mujer violada que recordó la cara de su agresor que resultó ser la cara que al mismo tiempo salía por televisión. El problema que en el ámbito jurisdiccional se plantea es que esta falsa atribución puede generar que las personas sean acusadas o incluso condenadas injustamente por delitos que nunca cometieron. Es más, muchas personas han sido absueltas por la prueba de adn, aunque en todos ellos hubo testigos presenciales que les situaban en el lugar de los hechos o incluso que les identificaron como los autores. Los testigos que solo vieron una parte del rostro del infractor, luego lo recuerdan de forma completa, debido a que el cerebro reconstruye la información que le falta o la suple (Gazzaniga, 2006: 138-140). 5) La sugestionabilidad, que incorpora nueva información aportada por otras personas, amigos, familiares, medios de comunicación, etc. (Schacter, 2003: 141-170). En un juicio oral en el que se le pregunta al testigo si recuera qué clase de arma llevaba el infractor, es muy posible que de forma automática aparezca un arma de fuego como un recuerdo sugestionado, que suele producirse con mayor facilidad en personas de corta o de avanzada edad (Gazzaniga, 2006: 139-140). 6) La tendenciosidad o propensión (Schacter, 2003: 171-190), es un error memorístico que contiene varios sesgos, como el de la coherencia, que tiende a considerar que las creencias anteriores y los sentimientos actuales son parecidos a los del pasado; el del cambio, que se produce cuando se exagera los efectos de algo, como por ejemplo de una dieta, enalteciendo los efectos de la misma que puede que no sean tan reales; el del egocentrismo, que consiste en una tendencia a perfeccionar la imagen del yo; el de la valoración retrospectiva, que se produce cuando, v.g., se le presenta a un jurado una prueba que el tribunal no admite, y se le da instrucciones para que no tenga en cuenta esa prueba para el veredicto. En estos casos el jurado tiende a condenar sin haber visto esa prueba inadmitida (Gazzaniga, 2006: 104-144). 7) La persistencia, (Schacter, 2003: 199-225), que consiste en que determinada información que se desea suprimir, aparece de forma recurrente impidiendo que se pueda olvidar. Aunque no influye en las declaraciones de los testigos en los procesos judiciales, sí afecta, en cambio, a los testigos y víctimas, sobre todo si se trata de delitos violentos.

Por todo ello, Gazzaniga señala que el cerebro es propenso al recuerdo erróneo y la cuestión es si existe distinción entre los modos en que el cerebro almacena recuerdos verdaderos o falsos. Existen varios experimentos con técnicas de $\mathrm{fMRI}$ que demuestran que se activan zonas del cerebro dependiendo de si el recuerdo es verdadero o es falso, lo que podría ser una importante herramienta para el sistema judicial, cuyos fundamentos se irán transformando a medida que la neurociencia vaya descubriendo más cuestiones importantes sobre el sistema de la memoria. De ese modo, la prueba de testigos ofrecerá muy poca fiabilidad para los jueces, tal y como ya sucede para los neurocientíficos, pues «la memoria 
no es tanto un mecanismo para recordar el pasado cuanto un medio para prepararnos para el futuro» (Gazzaniga, 2006: 145-148). Molina Galicia señala que debido a que el objetivo de la memoria es proporcionar coherencia en cada historia que registra la persona como un acontecimiento de su vida, la información que le falte será suplida mediante la incorporación o creación artificial de recuerdos falsos. Por eso incide en que aunque la capacidad de los testigos para percibir la realidad que presencian no se pone en duda y se viene aceptando de forma tácita, es algo que debe cambiar, sobre todo en el ámbito penal, siendo necesario incluso una serie de pruebas en el testigo que demuestran su capacidad de percepción, sin olvidar que muchos otros factores distorsionan los recuerdos, etc. (Molina Galicia: 2013: 68-69).

En el momento actual, nos encontramos con que muchos procesos se han resuelto contando exclusivamente con la declaración de la víctima que ha servido para desvirtuar la presunción de inocencia (Fernández Fustes, 2004: 294-296), y existe una doctrina jurisprudencial consolidada que así lo entiende (v.g. las Sentencias de la Sala de lo penal del Tribunal Supremo español de 13 de noviembre de 2010, de 12 de marzo de 2002, de 4 de abril de 2000, de 16 de marzo de 2001). También sucede que el testimonio de la víctima en ocasiones es contradictorio en los detalles, produciéndose variaciones en el relato debido a la volatilidad de los recuerdos, sobre todo las víctimas de delitos violentos suelen experimentar episodios amnésicos o incluso negacionistas de los hechos, dificultades de comunicación y percepción, etc. (Pecharromán Lobo, 2007: 344). Por último, suele ser muy frecuente que una serie de testigos presenciales de los hechos, no coincidan entre sí en sus declaraciones incurriendo en respuestas distintas sobre pequeños detalles, aunque sí relatan lo esencial que recuerdan, que suele coincidir en lo medular entre todos ellos y con las de una de las partes en el proceso. En ocasiones, las declaraciones de los testigos tampoco coinciden exactamente con lo que afirma el acusado o la víctima, o con ninguna de las dos versiones el relato es exactamente idéntico. ¿Significa esto que son testigos falsos, que no han presenciado los hechos o que tratan de favorecer o perjudicar a alguna de las partes? Sencillamente, no creo que estemos en condiciones de afirmarlo, debido a lo que la neurociencia ha podido comprobar respecto de la indisponibilidad de los datos que se almacenan en la memoria, la falta de control sobre los recuerdos que se almacenan o se eliminan, y respecto a las mutaciones de la realidad almacenada que conforme a los experimentos llevados a cabo por Schacter (a los que nos hemos referido supra) sabemos que suceden. Si se toman en consideraciones los conocimientos que se tienen sobre la memoria, el funcionamiento del cerebro y la multitud de variables que pueden concurrir en un testigo para que su declaración incurra en algún tipo de imprecisión, estas soluciones estarían siendo inapropiadas, por lo que considero que todas estas cuestiones deben ser tenidas en cuenta para el futuro de la jurisdicción y del proceso. 


\subsection{La detección de mentiras en el proceso}

El segundo aspecto es el relativo a la posibilidad de detección de mentiras mediante imágenes cerebrales, lo que nos conduciría a un posible replanteamiento del proceso penal en relación a la prueba de testigos, de peritos, interrogatorio del acusado, etc. En realidad, la idea de incorporar al proceso mecanismos tecnológicos por los que comprobar si un sujeto está mintiendo no es nueva, sino que aparece a finales del siglo xix y principios del xx, con Angelo Mosso y Cesare Lombroso, que trataron de ofrecer una estructura para medir los cambios fisiológicos que evidencian la mentira. Sin embargo, las modernas técnicas para el análisis de la comunicación no verbal, se centra en el estudio de las microexpresiones faciales que en todas las culturas conocidas se registran como signos expresivos incontrolables que se traducen en la exteriorización de estados mentales concretos. Para este objetivo se ha desarrollado un programa informático que es capaz de detectar las variaciones que experimentan cuarenta y cuatro músculos faciales asociados al miedo, a la desconfianza, a la angustia y al engaño, de modo que las respuestas que una persona ofrece ante las preguntas que se le formulan, pueden evidenciar cualquiera de estos sentimientos personales a través de sus movimientos espontáneos e incontrolables. Sumado a lo anterior, el siguiente paso es la inclusión de las técnicas de escáner cerebral para identificar las zonas cerebrales que se activan ante determinadas respuestas, y que están relacionadas con las emociones y el control cognitivo (Schacter, 2003: 7071).

En efecto, las imágenes captadas por la tecnología neurocientífica -en concreto la resonancia magnética nuclear funcional (fRMI)- permite identificar con claridad si un testigo miente, si una persona tiene un recuerdo porque ha presenciado un hecho o si ese recuerdo lo tiene porque ha cometido el hecho, e incluso se puede identificar si un recuerdo es adquirido o construido. Gazzaniga explica que Daniel Langleben y un grupo de investigadores de la Universidad de Pensilvania, a través de un experimento al que denominaron "Test de Conocimiento Culpable», detectaron distintas actividades cerebrales cuando las personas estudiadas mentían o cuando decían la verdad (Gazzaniga, 2006: 117-119). La siguiente cuestión es determinar si sería posible someter a esta clase de test a los testigos en los procesos judiciales, con carácter previo a que se les reciba declaración, para fijar una serie de patrones de actividad cerebral para que posteriormente durante su declaración, pueda saberse en cuál de las situaciones se encuentra el testigo, pues esta clase de técnicas podría arrojar buenos resultados y mejorar la calidad de la administración de justicia, (Martínez-Buján Pérez: 2013: 12).

Por otra parte, existe una técnica que está cada vez más desarrollada denominada "evaluación informatizada del conocimiento (CKA)", también llamada método de potencial de evocación cognitiva, que consiste en que se realiza una medición de las oscilaciones de la onda cerebral llamada 
P300 (descubierta en 1960), a través de electroencefalograma, con la finalidad de concretar la respuesta que da la persona sometida a estudio, ya que es posible identificar las variaciones de amplitud que experimenta dicha onda cuando la persona reconoce el olor, el sonido o la visión, de forma que se intensifica cuando lo que huele, escucha u observa le es conocido. De ese modo, esta técnica podría usarse para ciertos tipos de investigaciones, como por ejemplo, cuando se le muestran a un sujeto una serie de imágenes del escenario de un crimen y la respuesta cerebral medida por la onda P300, evidencia que ese lugar no le es conocido, por lo que podríamos descartar que esa persona hubiese estado implicada en la comisión del delito y también que lo hubiese presenciado como testigo. Esta técnica se utilizó en los década de los 80 del siglo pasado por Lawrence Farwell, que llamó a su método «huella cerebral» (Mora Teruel, 2007: 99), y fue utilizado en 1993 por el FBI para identificar que varios agentes de dicha fuerza de seguridad federal eran impostores porque no habían concluido su formación habilitante. Se realizaron experimentos similares en 2001, y este autor asevera que la CIA lo sigue utilizando aunque se desconoce con qué frecuencia y en qué medida, pero fue relevante su utilización por la policía de Missouri en el caso de James Grinder sobre violación, cuyos hechos cometidos en 1984, culminaron en 1998 consiguiendo incriminar al autor usando este método de Farwell. Otros casos como el de Terry Harrington, que cumplía una pena de prisión perpetua por unos hechos ocurridos en 1997, solicitó un nuevo juicio debido a que siempre defendió su inocencia alegando no haberlo cometido ni estar implicado en los hechos, aunque el juez encargado del caso admitió la prueba P300, no el método de huella cerebral de Farwell, y finalmente resolvió que la citada prueba no alteraba en nada el contenido del primer proceso, por lo que desestimó la solicitud de celebrar un nuevo juicio. No obstante, en un momento posterior, se accedió a la solicitud del Sr. Harrington y finalmente fue exonerado, tras haber permanecido veintitrés años en una cárcel norteamericana privado de libertad.

En España se utilizó recientemente esta prueba P300 en dos ocasiones, la primera en el caso de Pilar Cebrián en 2012, en el que se le realizó la prueba a su esposo, Antonio Losilla. La segunda en el caso del asesinato de Marta del Castillo, en el que, a pesar de existir una condena firme para los autores (Sentencia de la Audiencia Provincial de Sevilla, Sección Séptima, núm. 1/2012, de 13 de enero de 2012, y posteriormente la Sentencia de la Sala de lo Penal del Tribunal Supremo, núm. 62/2013, de 29 de enero de 2013), el cadáver no consiguió encontrarse. Uno de los condenados, Miguel Carcaño, aceptó someterse a la prueba que se llevó a cabo el día 6 de marzo de 2014 por el que fuera jefe del servicio de neurofisiología del hospital Miguel Servet de Zaragoza, el Dr. José Ramón Valdizán, y consistió en proyectarle imágenes de lugares en los pudiera estar escondido el cadáver de la joven asesinada en 2009, mientras se medían las variaciones en la amplitud de la onda. A pesar de que se identificaron algunas variaciones ante determinadas imágenes, el cuerpo no se consiguió encontrar, aunque sirvió para descartar otras zonas a las que refirió en las 
siete versiones distintas que ofreció Miguel Carcaño sobre la ubicación del cadáver y en las que se llegaron a gastar más de seiscientos mil euros de dinero público en las tareas de búsqueda.

En el caso hipotético de que consiguiéramos implementar una técnica que nos permitiera identificar si un testigo falta a la verdad en su declaración ante un tribunal, el primer interrogante que se plantea es la posibilidad de poner en entredicho las normas procesales de valoración de la prueba (Nieva Fenoll, 2013: 176-178), de forma que podrían quedar afectadas por la introducción de esta tecnología en el proceso, la libre valoración de la prueba y las reglas de la sana crítica, que implican que la valoración por el órgano jurisdiccional de los medios probatorios no se rige por criterios o reglas legales (Borthwick, 2001: 297), sino que en las sentencias deberá expresarse con claridad la relación entre los hechos que han sido declarados probados y los medios concretos de prueba que los sustentan (Cafferata Nores, 1998: 44-49). Lo que ahora se plantea es si desde esta incursión neurocientífica que permite identificar la veracidad de la declaración de los testigos, esa prueba puede seguir siendo valorada libremente por el juzgador, o si, por el contrario, atendiendo a la detección de mentiras en el proceso, la prueba testifical debe experimentar una transformación hacia un sistema de valoración legal, porque, en definitiva, sería imposible engañar a los jueces (RUBIA, 2011: 1). Sin duda se trata de una cuestión que nos invita a replantearnos nada menos que los fundamentos de la actividad probatoria en el proceso jurisdiccional. Es más, podríamos incluso llegar a cuestionar si la libre valoración de la prueba es realmente un proceso «libre», en la medida en que el juez igualmente podría hallarse condicionado por procesos neuronales que determinasen sus decisiones, tal y como mantienen los neurocientíficos cuando niegan la capacidad de decisión libre y voluntaria.

No obstante, autores como Pardo y Paterson plantean importantes objeciones a la utilización de la neurociencia para la detección de mentiras en el proceso, diciendo que es un claro ejemplo de confusión entre científicos y juristas acerca de la "distinción entre evidencias criteriales e inductivas y adscriben incoherentemente propiedades de un todo (una persona) a sus partes (regiones del cerebro)». Estos autores afirman que los distintos métodos conocidos de detección de mentiras, comparten el rasgo común de que la mentira supone "correlatos neurológicos estables» que se pueden detectar. En los polígrafos aumenta el ritmo cardíaco y la respiración experimenta modificaciones, mientras que en las técnicas de neuroimagen se incrementa el flujo sanguíneo en determinadas áreas cerebrales (Pardo / Paterson, 2011: 18-19). Las objeciones que aducen estos autores se centran en que, si bien algunas actividades cerebrales son necesarias para llevar a cabo un engaño, identificar esa actividad neuronal con un verdadero engaño es un error conceptual, ya que hay que distinguir dos cuestiones: la primera es que unas regiones del cerebro deciden si mentir y cuándo hacerlo; y la segunda es que, en un momento posterior a esas decisiones, emprenden un proceso distinto por el que deciden si llevar a cabo tal decisión previa. Del mismo modo, antes de decidir si mentir y 
cuándo hacerlo, la actividad neuronal viene a identificar una "mentira indirecta», ya que la neuroimagen deja al descubierto los conocimientos, la información o las intenciones que aparecen almacenadas en el cerebro. De ese modo, la evidencia criterial de la mentira es tan solo de comportamiento, no de neurología, independientemente de que sea la forma en la que el cerebro toma la decisión de mentir o el modo en que almacenan ciertos conocimientos o intenciones. Así, el propio concepto de engaño implica que se debe conocer la verdad previamente o al menos creer que algo es verdad, al tiempo que también implica que decir lo contrario es mentira, lo cual supone ejercer una suerte de juzgamiento sobre las creencias y también sobre los conocimientos que puedan tener los espectadores. La evidencia neurocientífica puede proporcionar la correlación entre ese comportamiento y los estados cerebrales y, en ese sentido, solo puede aportar una medición de la mentira pero no su completa medida, por lo que es conceptualmente erróneo llegar a la conclusión de que la mentira tiene lugar en el cerebro cuando una región cerebral toma la decisión de mentir, y también es erróneo afirmar que la neurociencia tiene la capacidad de sacar a relucir las mentiras que se generan en el cerebro, o incluso de concretar si en el cerebro hay almacenado un determinado conocimiento, información o intenciones, porque si posteriormente el comportamiento asociado a la mentira no coincide con los estados cerebrales constatados mediante neuroimágenes, el propio comportamiento eliminará la validez de la evidencia inductiva afirmada por la neurociencia. Por ello, lo único que puede afirmarse desde la neurociencia es que algunos estados cerebrales son necesarios para engañar, pero no son condición suficiente -ni la única condición-para que se produzca el engaño (Pardo / Paterson: 2011: 20-21).

Por su parte Molina Galicia manifiesta que los detectores de mentiras -en sus distintas modalidades- pueden ser medios probatorios en determinados casos con sujeción a ciertos límites y cautelas, pero nunca podrán ser considerados como pruebas concluyentes (Molina Galicia, 2013: 71-73). También Gazzaniga afirma que las pruebas para la detección de mentiras como la evaluación informatizada del conocimiento (CKA), plantean numerosas dudas, por lo que contienen escasa validez científica. En ese sentido afirma que en el ámbito del proceso penal, estas técnicas deberán adaptarse a cada caso y que además los resultados dependerán de las imágenes que se elijan para realizar la prueba, pero que en cualquier caso, no podrá descartarse la existencia de falsos positivos que podrían venir generados por falsos recuerdos o por otros factores influyentes. «La neurociencia no dispone todavía de datos incontrovertibles sobre cómo se representan los pensamientos en los encefalogramas, y mucho menos en el cerebro, y puede que nunca logremos leer el pensamiento, aunque éste siempre se genere en el cerebro». Por ese motivo -sigue diciendo- "es preciso alejar de los tribunales de justicia los detectores de mentiras basados en test cerebrales y la inducción farmacológica de estados mentales, porque las tecnologías de "lectura de mente" en realidad no logran leerla. Solo son un conjunto de datos que se debe interpretar en su 
contexto. La neurociencia lee cerebros, no mentes. La mente, aunque depende enteramente del cerebro, es un animal totalmente distinto» (Gazzaniga, 2006: 122-133).

Además, este mismo autor incide especialmente en que la utilización de la neurociencia en los procesos jurisdiccionales es desaconsejable, porque no hay dos cerebros idénticos, por lo que los patrones de actividad no pueden reputarse normales $o$ anormales para otorgarles un tratamiento generalizado; y tanto la mente como las emociones y la forma de pensar, están continuamente experimentando mutaciones, por lo que la neuroimagen es incapaz, por sí misma, de evidenciar lo que sucedía en el momento de la acción delictiva, sin olvidar la sensibilidad que presentan los cerebros de las personas ante los estímulos como el café, el alcohol, las drogas tóxicas, estupefacientes o sustancias psicotrópicas, menstruación, cansancio, etc., pero sobre todo, las imágenes cerebrales obtenidas con tecnología neurocientífica, son prejuiciosas porque aducen certeza clínica en algo en lo que no puede afirmarse más que la incerteza. Pero, la puerta queda abierta para este autor, puesto que no termina de negar que la neurociencia pueda servir eficazmente a estos fines debido a que avanza a gran velocidad y es posible que pronto se obtengan nuevos resultados que permitan conocer mejor el cerebro y la conducta de las personas, y por si acaso es conveniente que estemos preparados (Gazzaniga, 2012: 241-242). A ese fin pretendo contribuir aunque sea mínimamente con estas líneas.

\subsection{La medición del dolor en el ámbito del proceso}

Otro aspecto es el relativo a la medición del daño en el ámbito de cualquier proceso, ya que, si a través de métodos de resonancia magnética nuclear funcional ( $\mathrm{fMRI}$ ) se presentara la posibilidad de medir la intensidad del dolor que haya podido experimentar una persona como consecuencia de una lesión física o de un trauma psicológico tras haber sido víctima de un delito o de un accidente, la mejoría que experimentaría la administración de justicia sería de enorme relevancia (Taruffo, 2013: 1617). Estas cuestiones podrían, en un futuro no muy lejano, ofrecer una respuesta satisfactoria para las dificultades que actualmente se presentan para la determinación del daño moral, ya que su concreción siempre se basa en criterios orientativos, de aproximaciones o valoraciones subjetivas poco precisas y que han venido generando no pocos inconvenientes en el Derecho procesal de nuestros días. Los principales problemas en este ámbito derivan de que suele ser frecuente que las personas que acuden a un proceso -ya sea civil, laboral o penal- en el que reclaman indemnizaciones derivadas del dolor que hayan podido sufrir, lo exageran o mienten acerca del mismo con la finalidad de obtener una indemnización, aumentar la cuantía de la misma, o justificar la aparición de alguna enfermedad o limitación funcional y orgánica que justifique el derecho a una pensión, etc. Quizás la solución venga de la mano de la neurociencia y consiga poner fin al enorme vacío que, desde tiempos 
remotos, la praxis judicial ha venido soportando en esta complicada materia.

De entre las opiniones más recientes que se han ocupado de las dificultades existentes para la prueba del dolor, destaca la de Picó i Junoy, que ha puesto de manifiesto que la posibilidad de probar el dolor $-\mathrm{y}$ también la mentira- a través de imágenes del cerebro por medio de computadoras, merece una valoración crítica, por cuanto que se trata de imágenes que podrían cumplir una función auxiliar y de ayuda al tribunal para resolver en cada asunto, pero no son por sí solas capaces de aportar la solución definitiva y no permiten prescindir de las reglas de la sana crítica en su utilización, sobre todo si se tiene en cuenta que todavía existen serias dudas científicas y filosóficas sobre su fiabilidad. Por ello, siempre habrá que realizar una labor de valoración conjunta del resto de pruebas que se produzcan en el proceso con los informes periciales en los que se fundamenten esas neuroimágenes que evidencien el dolor (Picó i Junoy, 2013: 95).

Este autor parte de que el dolor es un hecho subjetivo que es percibido por el cerebro, de modo que sin esa percepción, desaparece el objeto de la indemnización. Hay que partir de la distinción entre dolor físico, que se produce por alteraciones en el cuerpo que producen lesiones externas o internas; y dolor psíquico, que consiste en una afectación al estado de ánimo y se produce, por ejemplo, cuando fallece un ser querido o se produce una situación trágica del tipo que sea. Del mismo modo, dolor y daño moral también son realidades distintas, aunque en ocasiones se confunden porque suelen ir unidas. Lo más habitual es que exista daño moral y dolor al mismo tiempo, pero el dolor desaparece antes que el daño moral como sucede cuando a una persona le queda una cicatriz, ya que en esos casos el dolor desaparece pronto pero la cicatriz perdura para siempre. También es posible que concurra daño sin dolor, como en el caso del sujeto que tras un accidente queda tetrapléjico y carece de sensibilidad en las extremidades y no puede sentir dolor, aunque el daño moral es realmente elevado. Por último, puede darse el caso de que exista dolor sin daño moral indemnizable, en situaciones como la que sucede cuando a una persona con un determinado credo religioso se le obliga a hacer algo en contra de sus creencias, en cuyo caso, dolor no hay pero daño moral sí, aunque no es indemnizable (Picó i Junoy, 2013: 83-85).

Derivado de lo anterior, cuando se trata de demostrar la existencia del dolor, el problema no solo es el de su debida acreditación, sino también la identificación de su exageración o de su invención, por lo que los distintos ordenamientos jurídicos han venido proporcionando soluciones tendentes a la objetivación, a través de baremos o de criterios jurisprudenciales (De Urbano Castillo, 2008: 26-27). A pesar de ello, muchos otros ámbitos quedan fuera de esta objetivación por lo que deviene necesaria la prueba del dolor en casos como, por ejemplo, cuando se difunde una imagen personal de un determinado contenido en las redes sociales $\sin$ el consentimiento del titular, o como cuando se cancela un vuelo y el pasajero no llega a tiempo a su destino, etc. Como afirma Picó i Junoy, las personas 
solo tenemos la percepción del dolor propio, no del dolor ajeno al que solo nos podemos aproximar, de modo que el juzgador nunca podrá tener por probado el dolor con certeza. Es más, la aproximación subjetiva al dolor ajeno se lleva a cabo gracias a la función que cumplen las neuronas espejo (Gazzaniga, 2012: 197) que posibilitan lo que comúnmente se conoce como "ponerse en la piel del otro», funciones que en ciertas psicopatías no pueden cumplirse por alteraciones en dichas neuronas. Desde ese punto de vista, dependiendo de la intensidad con que dichas funciones se produzcan en la actividad cerebral del juzgador, esa medición de dolor podrá experimentar también variaciones en cada caso, por lo que la objetividad en la apreciación de la realidad del dolor ajeno resulta imposible de alcanzar.

Por todo ello, Picó i Junoy asevera que la fórmula probática del dolor podría ser la que combinase, por una parte, la prueba pericial (que sería la de mayor relevancia) en la que se podrían incluir tanto las escalas de medición del dolor con intervención de especialistas en anestesiología y reanimación, radiólogos, neurólogos y neurocirujanos, que puedan interpretar correctamente las imágenes captadas mediante métodos neurocientíficos y su posteriores avances; y, por otra parte, la intervención de psicólogos que dictaminasen la evolución de la conducta de la persona afectada por el dolor, la aportación documental de historiales médicos de las personas aquejadas de esos dolores, el interrogatorio de la propia persona, que va a permitir un contacto directo con el juez que, a través de la inmediación, podrá comprobar ciertos datos que le permitan formarse una opinión más cercana a la realidad; el interrogatorio de testigos, que pueden también arrojar algo de luz sobre ese aspecto concreto; el reconocimiento judicial de la propia persona con la asistencia del médico forense; $y$, por último, las presunciones que también pueden ser efectivas para identificar actitudes tendentes a falsear la realidad (Picó i Junoy, 2013: 93-95). 
Los avances en el terreno de la neurociencia tienen una innegable incidencia en el ámbito del Derecho, por lo que ninguna de sus disciplinas debería darle la espalda. Existen razones más que suficientes para emprender un profundo debate filosófico que, desde el conocimiento que actualmente se tiene sobre el funcionamiento del cerebro, consiga armonizar el actual estado de la ciencia con el entramado de normas que rigen la convivencia pacífica en las sociedades civilizadas.

La neurociencia irrumpe de forma decisiva en el proceso jurisdiccional y aunque todavía no se conoce con exactitud el alcance que los nuevos descubrimientos podrán llegar a tener para la trasformación del proceso, se necesita una serena reflexión encaminada a sentar las bases que han de servir para fundamentar una revisión importante de algunos aspectos para la mejora del sistema.

No obstante, nos encontramos todavía en una fase que no permite una incursión neurocientífica muy enérgica en el proceso jurisdiccional, ni tampoco podemos esgrimir argumentos demasiado entusiastas en apoyo de su implementación, pero sí podemos afirmar que el debate filosófico sobre la necesidad de la utilización de la neurociencia al servicio de la administración de justicia, es ya impostergable.

\section{Bibliografia}

Balbuena PÉREZ, D.E., (2013): Derecho penal, Neurociencia y libertad. Una aproximación teórica al replanteamiento de la responsabilidad penal a propósito de las aportaciones neurocientíficas sobre el proceso mental para la formación de la voluntad. Marben, Asunción.

Bentham, J., (1843): Tratado de las pruebas judiciales. Compilado de los manuscritos del autor por Esteban Dumont. Traducción de Manuel Ossorio Florit (2001). Comares. Granada.

BORTHWICK, A.E.C., (2001): Nociones fundamentales del proceso. O una selección -de elite- de autores de Derecho procesal abordando los temas trascendentales del proceso. Corrientes, Mave. 
Cafferata Nores, J.I., (1998): La prueba en el proceso penal. 3a Ed. Depalma, Buenos Aires.

De Urbano Castrillo, E., (2008): «Responsabilidad civil derivada de un ilícito penal. Criterios para la determinación de los daños morales». En Revista Sepín Responsabilidad civil y seguro, núm. 4.

Demetrio CRESPO, E., (2011): «Libertad de voluntad, investigación sobre el cerebro y responsabilidad penal. Aproximación a los fundamentos del moderno debate sobre Neurociencias y Derecho penal». En InDret. Revista para el análisis del Derecho. 2/2011.

DIGES, M., (1997): Los falsos recuerdos. Sugestión y memoria. Paidós, Barcelona.

FERNÁNDEZ Fustes, M.D., (2004): La intervención de la víctima en el proceso penal. (Especial referencia a la acción civil). Tirant lo Blanch, Valencia.

GazzAniga, M.S., (2006): El cerebro ético. Traducción del Marta Pino Moreno. Barcelona, Paidós.

GAZZANIGA, M.S., (2012): ¿Quién manda aquí? El libre albedrío y la ciencia del cerebro. Traducción de Marta Pino Moreno. Paidós, Barcelona.

Gómez COLOMER, J.L., (2014): «La prueba: Los medios de prueba en concreto (V)». En Montero Aroca, J. / Gómez Colomer, J.L. / Montón Redondo, A. / Barona VILAR, S., Derecho jurisdiccional II. Proceso civil. 22a Ed. Tirant lo Blanch, Valencia.

LIBET, B., (1985): «Unconscious Cerebral Initiative and the Role of Conscious Will in Voluntary Action». The Behavioral and Brain Sciences, 8.

Martínez-Buján Pérez, C., (2013): «Prologo». En Ramos Vázquez, J.A., Ciencia, libertad y Derecho penal. (Aporías del determinismo y defensa de la libertad de acción como base del sistema penal). Tirant lo Blanch, Valencia. 
Molina Galicia, R., (2013): «Neurociencia, neuroética, Derecho y proceso». En Taruffo, M. / Nieva Fenoll, J., (Dirs.), Neurociencia y proceso judicial. Marcial Pons, Madrid-Barcelona-Buenos Aires.

Mora Teruel, F., (2007): Neurocultura. Una cultura basada en el cerebro. 2aㅡ Ed. Alianza editorial, Madrid.

Nieva FenolL, J., (2013): «Proceso judicial y Neurociencia: una revisión conceptual del Derecho procesal». En TARuffo, M. / Nieva FenolL, J., (Dirs.), Neurociencia y proceso judicial. Madrid-Barcelona-Buenos Aires: Marcial Pons.

PARDo, M.S. / PATERSON, D., (2011): «Fundamentos filosóficos del Derecho y la neurociencia». En InDret. Revista para el análisis del Derecho. 2/2011.

Pecharromán lobo, Y., (2007): «Victimología». En Collado Medina, J., (Coord.), Elementos básicos de investigación criminal. Madrid: Instituto Universitario «General Gutiérrez Mellado».

Pérez Manzano, M., (2011): «Fundamento y fines de Derecho penal. Una revisión a la luz de las aportaciones de la Neurociencia». En InDret. Revista para el análisis del Derecho. 2/2011.

Picó I Junoy, J., (2013): «La prueba del dolor». En TARuffo, M. / Nieva Fenoll, J., (Dirs.), Neurociencia y proceso judicial. Marcial Pons, Madrid-BarcelonaBuenos Aires.

RUBIA VILA, F.J., (2011): La revolución neurocientífica. Conferencia dictada en el 43을 Congreso de la European Brain and Behaviour Society. Sevilla, 10 de septiembre de 2011. [www.tendencias21.net].

RUBIA VILA, F.J. (2009): «El fantasma de la libertad: datos de la revolución neurocientífica». Crítica, Barcelona.

SCHACTER, D.L., (1999): En busca de la memoria. El cerebro, la mente y el pasado. Traducción de Borja Folch. Sine Qua Non, Barcelona.

SCHACTER, D.L., (2003): Los siete pecados de la memoria. Traducción de Joan Soler. Ariel, Barcelona. 
SOLER GIL, F.J. (2009): «Relevancia de los experimentos de Benjamin Libet y de John-Dylan Haynes para el debate en torno a la libertad humana en los procesos de decisión». En Thémata. Revista de Filosofía, núm. 41.

TARUFFO, M., (2013): «Proceso y neurociencia. Aspectos generales». En Taruffo, M. / Nieva Fenoll, J., (Dirs.), Neurociencia y proceso judicial. Marcial Pons, Madrid-Barcelona-Buenos Aires. 

